\title{
DENGUE EN EL PERÚ: A UN CUARTO DE SIGLO DE SU REEMERGENCIA
}

\author{
DENGUE IN PERU: A QUARTER CENTURY AFTER ITS REEMERGENCE \\ Cabezas César ${ }^{1,2, a}$, Victor Fiestas ${ }^{1,2}$, María García-Mendoza ${ }^{1}$ Miriam Palomino ${ }^{1}$, Enrique Mamani \\ Fernando Donaires ${ }^{1,2, a}$ \\ Centro Nacional de Salud Pública, Instituto Nacional de Salud, Lima, Perú. \\ Instituto de Medicina Tropical “Daniel A Carrión. Facultad de Medicina, Universidad Nacional Mayor de San Marcos, Lima, Perú. \\ Médico infectólogo. \\ Recibido: 24-02-15; Aprobado: 18-03-15
}

\begin{abstract}
RESUMEN
Un problema sanitario cada vez más frecuente y disperso en áreas tropicales y subtropicales del mundo, incluido el Perú donde ingresó en 1990, es el dengue. Es producido por el virus del dengue con cuatro serotipos y transmitido por el Aedes aegypti, vector que convive con los humanos y cuya presencia es favorecida por deficientes condiciones sanitarias, sociales y económicas. Manifestaciones de formas severas de la enfermedad como el choque y sangrado, están relacionadas con la frecuente cocirculación de los cuatro serotipos y la aparición de nuevos genotipos como el americano/asiático del serotipo 2 . La nueva clasificación de la enfermedad por la OMS como dengue con o sin signos de alarma y dengue grave, está contribuyendo a un diagnóstico y tratamiento más oportunos, permitiendo reducir la letalidad. Debe destacarse la necesidad de la vigilancia del síndrome febril y los índices aédicos que contribuyan a un diagnóstico oportuno y orienten las medidas de control vectorial mediante educación sanitaria y manejo ambiental con participación comunitaria e intersectorial, de manera creativa según los nichos ecológicos. Una alternativa de prevención complementaria sería la vacunación utilizando vacunas tetravalentes cuya seguridad y eficacia deben estar garantizadas antes de su uso poblacional en el marco de estrategias integrales.
\end{abstract}

Palabras clave: Dengue; Aedes aegypti; Enfermedades transmisibles emergentes (fuente: DeCS BIREME).

\begin{abstract}
A health problem each time more frequent and dispersed in tropical and subtropical areas of the world, including Peru where it entered in 1990, is dengue. It is produced by the dengue virus with four serotypes and transmitted by Aedes aegypti, a vector that coexists with humans and whose presence is favored by deficient sanitary, social and economic conditions. Manifestations of severe forms of the disease such as shock and bleeding, are related to the frequent co-circulation of the four serotypes and the emergence of new genotypes such as American / Asian serotype 2. The new classification of the disease by WHO as dengue with or without warning signs and severe dengue, is contributing to more timely diagnosis and treatment, enabling reductions in mortality. Of note is the need to highlight the surveillance of acute febrile illness and Aedes indices that contribute to a timely diagnosis and guide vector control measures through sanitary education and environmental management with community and intersectoral participation, in a creative manner according to ecological niches. An alternative for complementary prevention would be vaccination using tetravalent vaccines whose safety and efficacy must be guaranteed before its use in the population under the framework of comprehensive strategies.
\end{abstract}

Key words: Dengue; Aedes aegypti; Communicable diseases, emerging (source: MeSH NLM).

\section{INTRODUCCIÓN}

El dengue es un problema creciente para la salud pública en las áreas tropicales del mundo, es en la actualidad la enfermedad viral transmitida por mosquitos más importante que afecta a los seres humanos. Según la Organización Mundial de la Salud (OMS), se estima entre 50-100 millones las nuevas infecciones que se producen anualmente en más de 100 países endémicos (Figura 1).
En las últimas cinco décadas, la incidencia de dengue se ha incrementado 30 veces (Figura 2) documentándose casos en áreas previamente no afectadas. Cada año surgen cientos de miles de casos de dengue grave, con aproximadamente 20000 muertes ${ }^{(2)}$.

Anualmente se pierden en el mundo 264 años de vida ajustados por discapacidad (DALY, por sus siglas en inglés) por millón de habitantes, con un costo estimado para

Citar como: Cabezas C, Fiestas V, García-Mendoza M, Palomino M, Mamani E, Donaires F. Dengue en el Perú: a un cuarto de siglo de su reemergencia. Rev Peru Med Exp Salud Publica. 2015;32(1):146-56. 


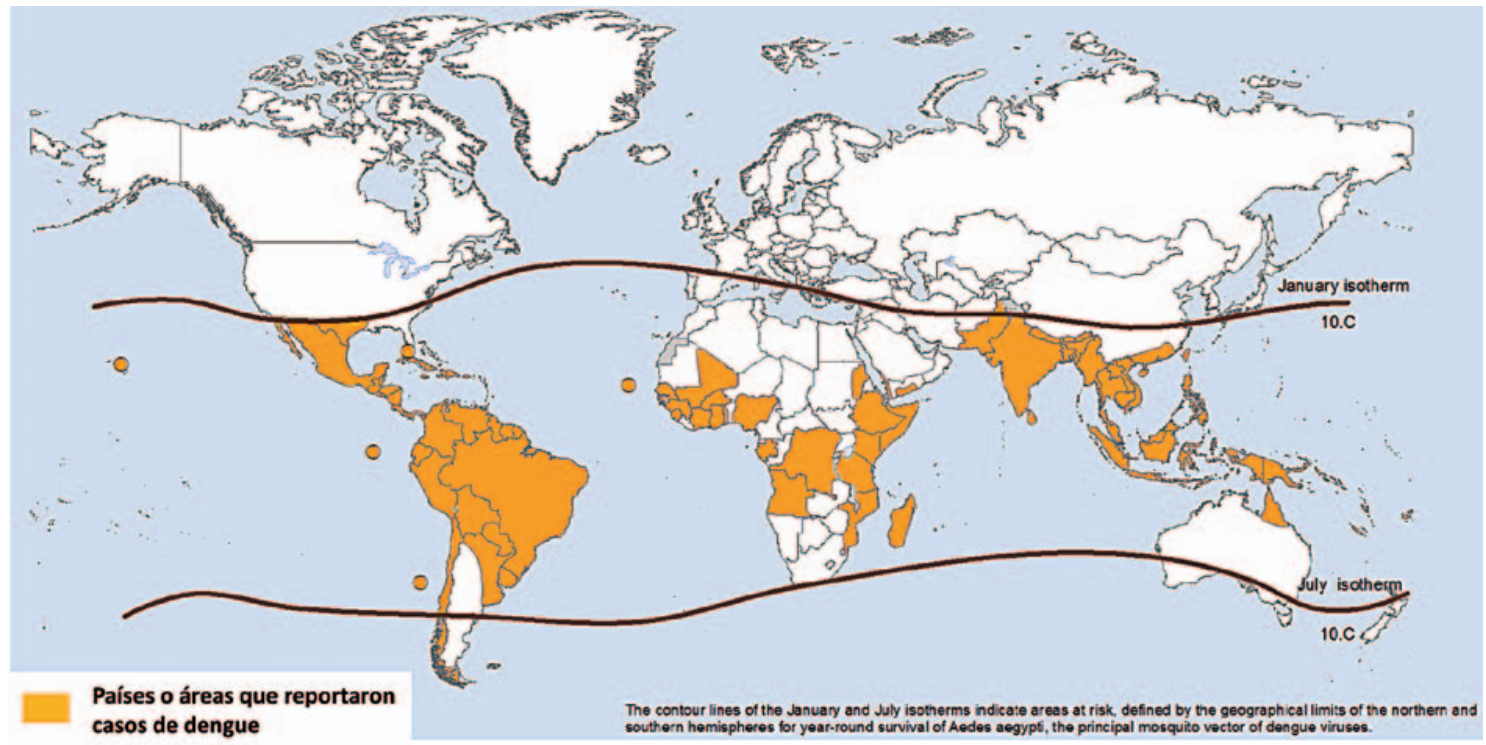

Figura 1. Distribución de los países y/o áreas de riesgo de transmisión de dengue en el mundo, $2013^{(1)}$. Fuente: xxxxxx

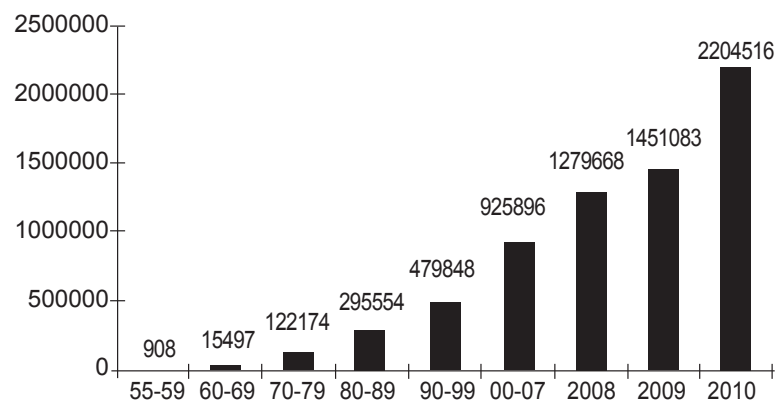

Figura 2. Número promedio de casos de dengue reportados anualmente a la OMS entre 1955-2007 y número de casos reportados en años recientes $2008-2010^{(2)}$

casos ambulatorios y hospitalizados de USD 514 - 1394, afectando mayormente a las poblaciones más pobres. En general, los números reales son probablemente mayores debido al subregistro y la clasificación errónea de casos de dengue ${ }^{(2)}$. En las Américas se ha calculado que el costo anual de dengue es aproximadamente 2 billones de dólares, de los cuales $60 \%$ corresponden a costos indirectos, principalmente pérdida de productividad ${ }^{(3)}$.

La emergencia o reemergencia del dengue en los diferentes países y en las diversas regiones geográficas dentro de los países, obedecen a la presencia de varios determinantes y una combinación de los mismos, que permiten la presencia del Aedes aegypti (también vector de la fiebre chikungunya). Entre estas determinantes deben considerarse: el cambio climático, la escasa disponibilidad de agua para consumo, el crecimiento poblacional sostenido, las intensas migraciones de áreas endémicas a áreas no endémicas de dengue, la persistencia de actividad epidémica en el interior del país y en los países limítrofes, la urbanización no controlada ni planificada, viviendas inapropiadas en centros urbanos, inadecuada disposición de residuos, uso cada vez mayor de envases no biodegradables en el medio así como neumáticos en desuso, el inadecuado saneamiento ambiental, el tránsito urbano, interprovincial y aéreo intenso. Igualmente, se debe destacar la aún deficiente coordinación intersectorial y la poca participación de organizaciones y población, por considerar que el problema del dengue es un problema del sector salud.

\section{DENGUE EN LA REGIÓN DE LAS AMÉRICAS}

En la región de las Américas el patrón es similar a la situación que se observó en Asia hace 30 años. Según datos de OPS/OMS, los casos de dengue se quintuplicaron en las Américas entre 2003 y 2013. Entre 2009 y 2012 se notificaron anualmente, en promedio, más de un millón de casos, y el 2013 fue uno de los años más epidémicos en la historia del continente, con más de 2,3 millones de casos, 37705 casos graves y 1289 muertes. Sin embargo, la letalidad por dengue disminuyó de 0,07 a $0,05 \%$ en los últimos tres años, una reducción que se atribuye al mejor manejo clínico de los pacientes a partir del $2010^{(4)}$.

En el 2014 se reportaron 1173248 casos de dengue (tasa de incidencia de 193,7 casos por 100 mil habitantes), 16008 casos de dengue grave y 684 fallecidos en la región de las Américas. La subregión del cono sur reportó el $52,1 \%$ de los casos, seguido por 
la subregión Norteamérica, Centroamérica y México $(25,2 \%)$ y la subregión andina $(20,7 \%)^{(5)}$. Los países de la región con una tasa de letalidad superior al promedio fueron: Brasil, Colombia, Ecuador, Guatemala, Panamá, Perú y República Dominicana, siendo este último el país con la mayor tasa de letalidad. Los cuatro serotipos se encuentran circulando en todo el continente y en ocho países se ha confirmado la circulación simultánea de todos ellos (Brasil, Colombia, Ecuador, Guatemala, México, Nicaragua, Perú y Venezuela) ${ }^{(6)}$.

\section{DENGUE EN EL PERÚ}

Los primeros reportes de brotes de un síndrome febril compatible con dengue clásico en el país fueron descritos en $1700,1818,1850$ y 1876 , aunque no se tuvo confirmación laboratorial (7). La reemergencia del dengue en el Perú en el siglo XX está ligado a la reintroducción del Aedes aegypti en 1984 (luego de su eliminación en 1956). En 1990 ocurrió una explosiva epidemia de dengue clásico por DENV-1 en las principales ciudades de nuestra Amazonía y, en la actualidad, casi todas

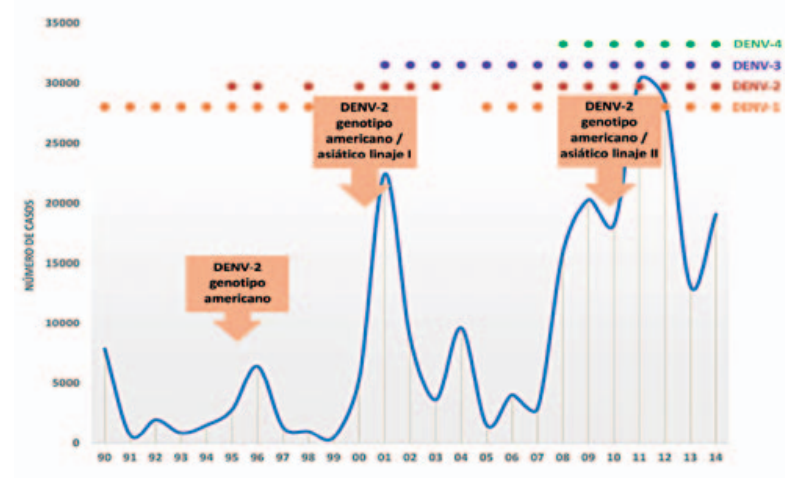

Figura 3. Evolución de los casos de dengue e introducción de serotipos en el Perú, 1990-2014.

Fuente: INS-DGE-MINSA

las áreas del país con presencia de Aedes aegypti presentan casos de dengue y la circulación de cuatro serotipos de dengue.

En la Figura 3 se muestra la evolución de casos de dengue registrados desde su ingreso al Perú en 1990 hasta el 2014, evidenciándose una tendencia al incremento en la

Tabla 1. Casos de dengue según departamentos en el Perú, entre los años 2000-2015*

\begin{tabular}{|c|c|c|c|c|c|c|c|c|c|c|c|c|c|c|c|c|}
\hline & \multicolumn{16}{|c|}{ AÑOS } \\
\hline & 2000 & 2001 & 2002 & 2003 & 2004 & 2005 & 2006 & 2007 & 2008 & 2009 & 2010 & 2011 & 2012 & 2013 & 2014 & $2015^{*}$ \\
\hline Loreto & 518 & 510 & 2499 & 784 & 2580 & 1772 & 1995 & 1720 & 7232 & 3723 & 1322 & 21245 & 4382 & 4472 & 7594 & 654 \\
\hline Piura & 2620 & 11713 & 101 & 1726 & 37 & 51 & 865 & 282 & 1702 & 4029 & 8393 & 183 & 1181 & 1979 & 2890 & 386 \\
\hline Ucayali & 97 & 682 & 2977 & 182 & 1413 & 69 & 174 & 182 & 931 & 1069 & 121 & 1770 & 11056 & 1057 & 1587 & 273 \\
\hline Madre de Dios & 21 & 103 & 12 & 0 & 0 & 85 & 2 & 314 & 45 & 798 & 2952 & 1956 & 2047 & 2270 & 1383 & 88 \\
\hline La Libertad & 1496 & 5718 & 3 & 0 & 263 & 259 & 10 & 1482 & 267 & 134 & 728 & 17 & 104 & 23 & 64 & 3 \\
\hline San Martin & 218 & 179 & 42 & 46 & 577 & 172 & 170 & 677 & 541 & 448 & 307 & 1437 & 2322 & 1207 & 1746 & 188 \\
\hline Cajamarca & 18 & 1100 & 1176 & 114 & 383 & 1127 & 123 & 125 & 464 & 473 & 784 & 688 & 3208 & 85 & 318 & 22 \\
\hline Tumbes & 192 & 1803 & 13 & 50 & 1552 & 183 & 243 & 79 & 51 & 830 & 1177 & 104 & 592 & 250 & 1790 & 425 \\
\hline Lambayeque & 0 & 813 & 45 & 79 & 1868 & 804 & 77 & 656 & 718 & 674 & 291 & 10 & 491 & 25 & 195 & 111 \\
\hline Amazonas & 341 & 692 & 30 & 143 & 312 & 409 & 35 & 320 & 648 & 158 & 273 & 305 & 587 & 247 & 216 & 6 \\
\hline Junín & 7 & 48 & 207 & 116 & 192 & 114 & 189 & 378 & 8 & 245 & 140 & 87 & 736 & 779 & 563 & 178 \\
\hline Ancash & 0 & 4 & 824 & 1 & 8 & 4 & 1 & 8 & 77 & 224 & 50 & 0 & 1068 & 453 & 9 & 0 \\
\hline Huánuco & 29 & 159 & 132 & 107 & 356 & 143 & 128 & 28 & 110 & 257 & 214 & 136 & 336 & 67 & 172 & 26 \\
\hline Lima & 0 & 2 & 0 & 0 & 0 & 440 & 10 & 91 & 0 & 235 & 90 & 0 & 314 & 102 & 7 & 9 \\
\hline Pasco & 0 & 0 & 22 & 1 & 6 & 3 & 0 & 2 & 30 & 29 & 0 & 87 & 80 & 55 & 38 & 3 \\
\hline Cusco & 0 & 0 & 2 & 0 & 0 & 2 & 0 & 0 & 0 & 0 & 0 & 57 & 0 & 2 & 227 & 10 \\
\hline Puno & 0 & 0 & 0 & 0 & 0 & 0 & 0 & 0 & 0 & 0 & 0 & 2 & 1 & 2 & 14 & 4 \\
\hline Ayacucho & 0 & 0 & 0 & 0 & 0 & 0 & 0 & 0 & 0 & 0 & 0 & 0 & 0 & 1 & 1 & 4 \\
\hline Huancavelica & 0 & 0 & 0 & 0 & 0 & 0 & 0 & 0 & 0 & 0 & 0 & 0 & 0 & 0 & 0 & 0 \\
\hline Tacna & 0 & 0 & 0 & 0 & 0 & 0 & 0 & 0 & 0 & 0 & 0 & 0 & 0 & 0 & 0 & 0 \\
\hline Callao & 0 & 0 & 0 & 0 & 0 & 0 & 0 & 0 & 0 & 0 & 0 & 0 & 0 & 0 & 0 & 0 \\
\hline Apurimac & 0 & 0 & 0 & 0 & 0 & 0 & 0 & 0 & 0 & 0 & 0 & 0 & 0 & 0 & 0 & 0 \\
\hline Moquegua & 0 & 0 & 0 & 0 & 0 & 0 & 0 & 0 & 0 & 0 & 0 & 0 & 0 & 0 & 0 & 0 \\
\hline Arequipa & 0 & 0 & 0 & 0 & 0 & 0 & 0 & 0 & 0 & 0 & 0 & 0 & 0 & 0 & 0 & 0 \\
\hline Ica & 0 & 0 & 0 & 0 & 0 & 0 & 0 & 0 & 0 & 0 & 0 & 0 & 0 & 0 & 0 & 0 \\
\hline Total & 5557 & 23526 & 8085 & 3349 & 9547 & 5637 & 4022 & 6344 & 12824 & 13326 & 16842 & 28084 & 28505 & 13076 & 18814 & 2390 \\
\hline
\end{tabular}

Fuente: Red Nacional de Epidemiología (RENACE)-DGE-MINSA.

$\left.{ }^{*}\right)$ Hasta la semana epidemiológica 06 de 2015. 
última década, siendo los departamentos de la Amazonía y de la costa norte los más afectados (Tabla 1).

La presentación de casos graves y fatales en nuestro país tiene una clara correlación con el ingreso de un nuevo linaje del DENV-2 genotipo americano/asiático a finales del 2010 (Figura 4), que produjo una epidemia que tuvo gran impacto en la demanda de servicios de salud ${ }^{(8,9)}$. De esta manera, en el 2011 se registraron 22 087 casos de dengue sin señales de alarma $(88,5 \%)$, 2720 casos de dengue con señales de alarma $(10,9 \%)$, 158 casos de dengue grave $(0,6 \%)$ y 29 fallecidos ${ }^{(10)}$. Para el 2014 se notificaron 14537 casos de dengue sin señales de alarma, 4296 casos de dengue con señales de alarma y 95 casos de dengue grave, con una tasa de incidencia de 61,43 x 100000 habitantes ${ }^{(11)}$.

\section{EL VECTOR Y LA TRANSMISIÓN DE DENGUE}

El Aedes aegypti, originario de África, es el principal vector del dengue, pero también de la fiebre amarilla urbana (FAU). En 1947, el Programa continental de erradicación del Aedes aegypti para el control de la FAU de la OPS consiguió eliminar este vector en 18 países de la región, utilizando el insecticida organoclorado DDT. Sin embargo, el deterioro de este programa al final de la década del 60 facilitó su reintroducción a partir de las áreas que no habían logrado eliminarlo y actualmente, la mayoría de los países de las Américas están infestadas por Aedes aegypti ${ }^{(12)}$.

En el Perú, la reintroducción del Aedes aegypti fue detectada en 1984 en Loreto, luego se dispersó hacia regiones vecinas como San Martín y la selva central (Satipo y Chanchamayo), y hasta el 2011 se había

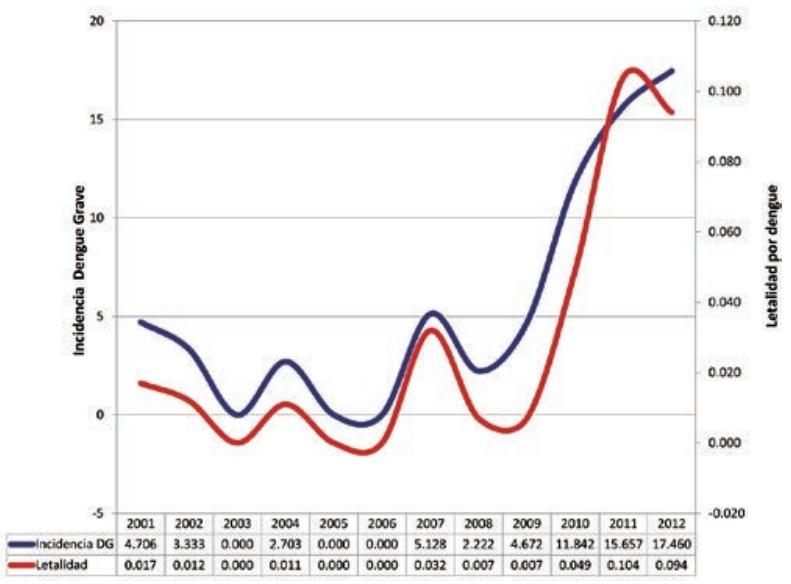

Figura 4. Incidencia de casos graves y letalidad por dengue en el Perú, 2001-2012.

Fuente: Estrategia Sanitaria Nacional de Malaria y OEM. MINSA.

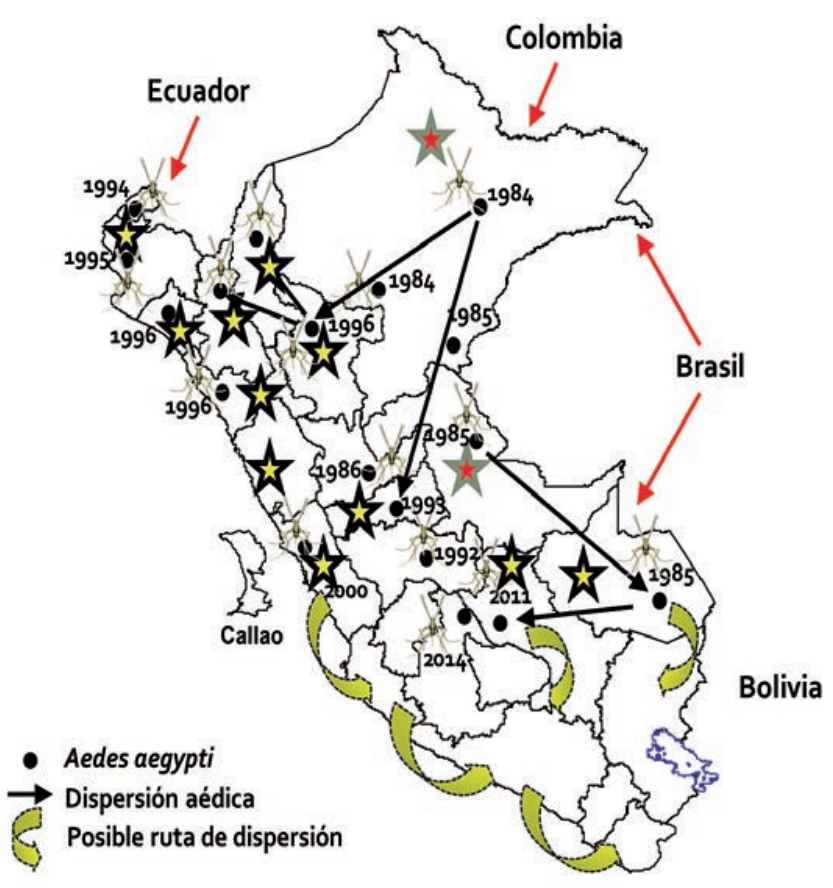

Figura 5. Distribución del Aedes aegypti según año de detección de su ingreso en el Perú.

Fuente: Instituto Nacional de Salud.

identificado en 269 distritos y 18 regiones (casi la tercera parte del país) (Figura 5). En Lima se registró por primera vez en el año 2000 en cinco distritos (La Victoria, El Agustino, Rímac, San Juan de Lurigancho y Cercado de Lima), posteriormente se extendió a otros 26 distritos de Lima y 3 distritos del Callao ${ }^{(13)}$. Por otro lado, la identificación de cinco haplotipos de Aedes aegypti en nuestro país nos indica que esta variabilidad genética se debería tanto a la migración activa del vector como a la migración pasiva mediada por la actividad humana ${ }^{(14,15)}$.

El Aedes aegypti es un mosquito peridomiciliario, se cría en recipientes sombreados y con agua limpia, en los cuales las hembras depositan sus huevos por encima del nivel del líquido, en las paredes de dichos recipientes. En lugares lluviosos (selva), los recipientes predilectos son los objetos desechados como llantas, latas, botellas o floreros, o cualquier recipiente que mantenga el agua de lluvia (Figura 6 A y B); en lugares no lluviosos (Lima), generalmente son los recipientes caseros utilizados para almacenar agua como barriles, tanques bajos y altos, tinajas y baldes (Figura $6 \mathrm{C}$ y D).

La expansión geográfica de los vectores y virus conllevó al incremento del uso de insecticidas piretroides. Por más de 20 años, el control del mosquito adulto se realizó utilizando insecticidas en aplicación ultra bajo volumen (ULV), siendo malatión el primer insecticida que fuera 

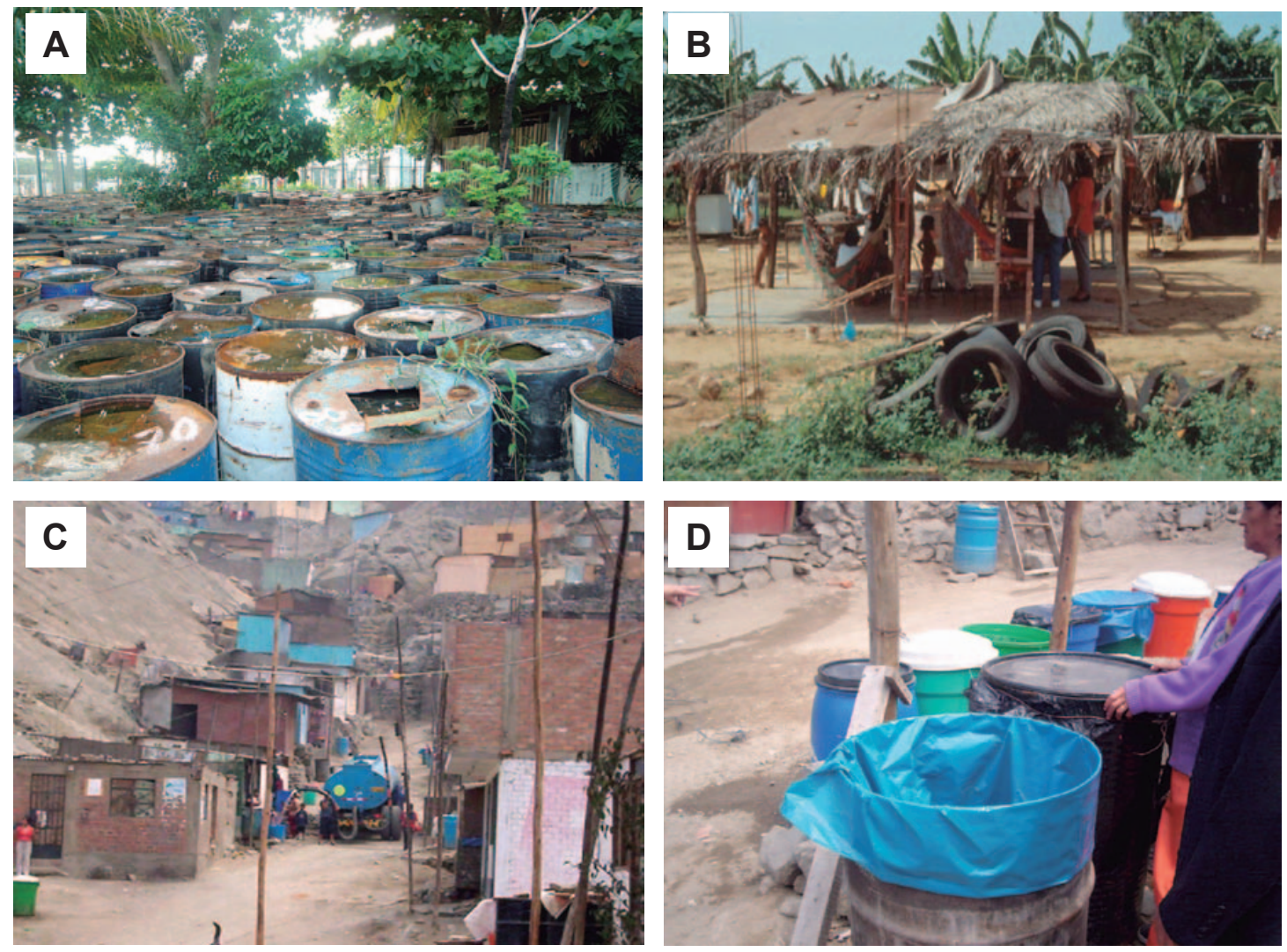

Figura 6. Condiciones que favorecen la reproducción del Aedes aegypti en el país.

aplicado con equipo pesado y con aeroplano. Han pasado más de 20 años para entender que el uso del ULV tiene poco impacto en la disminución de la transmisión del dengue, esto ha sido demostrado por investigaciones realizadas por el CDC quienes concluyeron que ni las aplicaciones ULV o las térmicas son efectivas para reducir la población de mosquitos adultos, debido a que son altamente domésticos y porque se esconden en interiores y lugares ocultos como los closets o armarios y simplemente el insecticida no entra en contacto con los insectos . Esta afirmación también se puede corroborar por la gran distribución geográfica del vector, a pesar de contar con un programa de control de vectores con el uso de insecticidas ${ }^{(13)}$.

Los insecticidas continúan siendo una herramienta importante en el programa de control integrado, sin embargo, su uso continuo ha originado una resistencia progresiva constituyendo un problema que requiere mantenerse en vigilancia ${ }^{(16)}$. En países como Brasil (17) y Colombia (18) se ha evidenciado resistencia de poblaciones naturales de Ae. aegypti a los insecticidas. El Perú no ha sido ajeno a esta situación y desde el año 2005 se ha detectado resistencia a los piretroides en las pruebas realizadas por el Instituto Nacional de Salud (INS) (resistencia a permetrina en Tumbes y a alfacipermetrina en Puerto Maldonado). En el 2007, Bisset et al. demostraron diferentes niveles de resistencia a insecticidas piretroides y al organoclorado DDT en Tumbes y Trujillo ${ }^{(19)}$. En el 2012, el INS reportó resistencia por verificar del Ae. aegypti a deltametrina en Nauta (Loreto).

\section{EL VIRUS}

El virus del dengue es un arbovirus («arbo» acrónimo del inglés "arthropod-borne", transmitido por artrópodos) que pertenece a la familia Flaviviridae, género Flavivirus. Este género incluye más de 70 virus agrupados por su relación serológica y por la determinación de secuencias genómicas, al menos 30 de estos virus causan enfermedad en los humanos.

El virus del dengue (DENV), es un grupo de cuatro virus estrechamente relacionados, pero antigénicamente distintos y denotados como serotipos: DENV-1, DENV2, DENV-3 y DENV-4. Recientemente se ha informado de la probable existencia de un quinto serotipo viral ${ }^{(20)}$, pero por el momento no se tiene mayor información 
científica disponible. Este serotipo se mantendría en el ciclo selvático a diferencia de los otros cuatro serotipos que siguen el ciclo humano. Su implicancia en la salud pública, así como sobre el uso de vacunas aun es controversial y está en discusión y se necesitan más estudios epidemiológicos y ecológicos para detectar cepas de dengue selváticos adicionales ${ }^{(21)}$.

EI DENV consiste en una molécula de RNA, de simple cadena, polaridad positiva de aproximadamente $11 \mathrm{~kb}$, que codifica para tres proteínas estructurales (C, prM/M, E) y siete proteínas no estructurales (NS) en el siguiente orden 5'-C-prM-E-NS1-NS2A-NS2B-NS3-NS4A-NS4BNS5-3'. La traducción y replicación del genoma de los virus ARN positivos ocurren asociadas a estructuras membranosas y, en particular en el caso de DENV, estos procesos ocurren en estrecha asociación a membranas y vesículas derivadas del retículo endoplasmático. Durante el proceso de traducción, las secuencias de translocación y de detenimiento de la translocación de la poliproteína determinan su topología en la membrana del retículo. Esta poliproteína es clivada co- y postraduccionalmente por proteasas virales y celulares dando las diez proteínas del virus ${ }^{(22)}$.

El Aedes aegypti introduce el virus dengue en nuestro organismo por la vía subcutánea y las células de Langerhans son las primeras células infectadas transportándolos a los ganglios linfáticos regionales para la presentación de antígeno a los linfocitos $T$ y $B$ (respuesta inmune adaptativa), mientras que en sangre periférica se disemina principalmente en los monocitos, pero también puede invadir otras células del organismo como: hepatocitos, neumocitos tipo II, fibras cardíacas, células dendríticas, células endoteliales y plaquetas ${ }^{(23,24)}$.

\section{GENOTIPOS Y LINAJES DEL VIRUS DENGUE CIRCULANTES EN PERU}

En el Perú se encuentran circulando los cuatro serotipos de dengue. En 1990 se introdujo DENV-1 a partir de la ciudad de lquitos ${ }^{(25-27)}$, en 1995 se introdujo el genotipo americano del DENV-2 ${ }^{(28,29)}$ y posteriormente, durante la epidemia de dengue en la costa norte del país en el 2000, fue identificado un linaje del genotipo americano/ asiático ${ }^{(30,31)}$. El DENV-3 fue reconocido a partir del $2001{ }^{(32)}$, DENV-4 a partir del $2008{ }^{(33)}$ y en 2010 , un nuevo linaje del genotipo americano/asiático fue aislado en la mayor epidemia de dengue en Loreto ${ }^{(9)}$.

En un estudio reciente realizado sobre la identificación de los genotipos y linajes de los cuatro serotipos del virus dengue que circularon en el país desde 1988-
2012 se identificó para el serotipo DENV-1, el genotipo $\mathrm{V}$ con tres linajes; respecto al serotipo DENV-2, se estableció dos genotipos: el genotipo americano con dos linajes y el genotipo americano/asiático con cinco linajes. El serotipo DENV-3, presentó el genotipo III con cinco linajes y finalmente se encontró que el serotipo DENV-4 tuvo dos linajes circulantes. De esta manera, se evidencia una alta variabilidad genética del virus dengue, siendo el DENV-3 más divergente con cinco linajes y el DENV-4 menos divergente con dos linajes, respecto a los otros serotipos estudiados ${ }^{(34)}$.

\section{ASPECTOS CLÍNICOS Y LA NUEVA CLASIFICACIÓN DE DENGUE}

La infección puede cursar de forma asintomática o manifestarse con un amplio espectro clínico que va desde las formas inaparentes o febriles con dolores de cuerpo a formas graves que incluyen al choque y alteración de la hemostasia con hemorragia o sin ella.

En el 2009, la OMS recomendó una nueva clasificación de la enfermedad debido a las dificultades observadas con la clasificación anterior, tenemos así: dengue sin signos de alarma, dengue con signos de alarma y dengue grave ${ }^{(35)}$. Esta nueva clasificación permite un mejor manejo de las formas no graves en los establecimientos del primer nivel de atención y la atención especializada de las formas graves en los establecimientos del segundo y tercer nivel de atención.

Entre los signos de alarma destacan el dolor abdominal intenso y continuo, vómitos persistentes, acumulación de fluidos clínicamente detectables, sangrado en mucosas, letargia o irritabilidad, hepatomegalia mayor a $2 \mathrm{~cm}$ y en el laboratorio aumento del hematocrito y reducción del número de plaquetas.

Las formas graves del dengue están asociadas con una mayor extravasación de plasma, que conlleva a acumulación de plasma en el tercer espacio, choque, distrés respiratorio, sangrado severo y daño severo de órganos (hígado, cerebro, corazón, riñón y otros órganos). Esta forma correspondió al 1\% de los casos notificados en el Perú durante el 2012 y 2013.

Después del período de incubación, la enfermedad se inicia bruscamente y pasa por tres fases clínicas: febril, crítica y de recuperación. La etapa febril que puede ser la única en la mayoría de los pacientes, está asociada a la circulación del virus en la sangre, tiene una duración variable que no excede los siete días ${ }^{(36)}$. En la mayoría de casos la evolución es hacia una mejoría luego de la 
caída de la fiebre; sin embargo, en algunos pacientes la caída de la fiebre se encuentra asociada al agravamiento del caso, siendo la defervescencia de la fiebre el heraldo del inicio de la etapa crítica de la enfermedad.

Durante la infección viral, la respuesta inmune innata es activada por el reconocimiento del material genético del virus a través de los receptores de reconocimiento de padrón que resulta en la producción de interferón tipo I ( $\alpha$ y $\beta$ ), así como citocinas y otros mediadores inflamatorios ${ }^{(37)}$. Usualmente en las infecciones virales la respuesta inmune es protectora; sin embargo, en el caso de la infección por dengue puede darse una respuesta protectora temporal y una respuesta inmune paradojal que se manifiesta por una respuesta con producción excesiva de citoquinas ("tormenta de citocinas") (38), cambio de la respuesta TH1/TH2 e inversión del índice CD4/CD8 ${ }^{(39,40)}$. Este desmesurado incremento de citoquinas aumenta la permeabilidad vascular, conllevando a extravasación del plasma, fenómeno que es esencial conocer para explicar la hipotensión y el choque distributivo que se produce, debido a la salida de agua y proteínas del intravascular al extravascular.

La apoptosis de los linfocitos T es un fenómeno inducido por la infección viral en los primeros días de la infección, lo cual puede limitar o agravar la infección por deterioro de la capacidad inmune del paciente ${ }^{(41)}$. También puede provocar daños en las células endoteliales y de órganos como el hígado, el corazón, el riñón o el cerebro. La plaquetopenia es una manifestación de destrucción de estas por fenómeno inmunológico y por depleción temporal en su producción, aunque la intensidad del sangrado no está en relación con los niveles de plaquetopenia (42-44). Las causas del sangrado es multifactorial e incluyen las alteraciones vasculares, alteraciones de los mecanismos de la coagulación y fibrinólisis ${ }^{(45)}$.

\section{DIAGNÓSTICO DE LABORATORIO}

El diagnóstico de laboratorio, eficiente y preciso es de fundamental importancia para la atención clínica, contribuye, a la detección temprana de casos graves, la confirmación de casos y el diagnóstico diferencial con otras enfermedades infecciosas, actividades de vigilancia, control de brotes, patogénesis, investigación académica, desarrollo de vacunas y pruebas clínicas.

La infección por dengue puede ser diagnosticada directamente detectando la presencia del virus, mediante el aislamiento en cultivo celular, detectando el ARN mediante técnicas moleculares o detectando el antígeno de la glicoproteína no estructural 1 (NS1); de manera

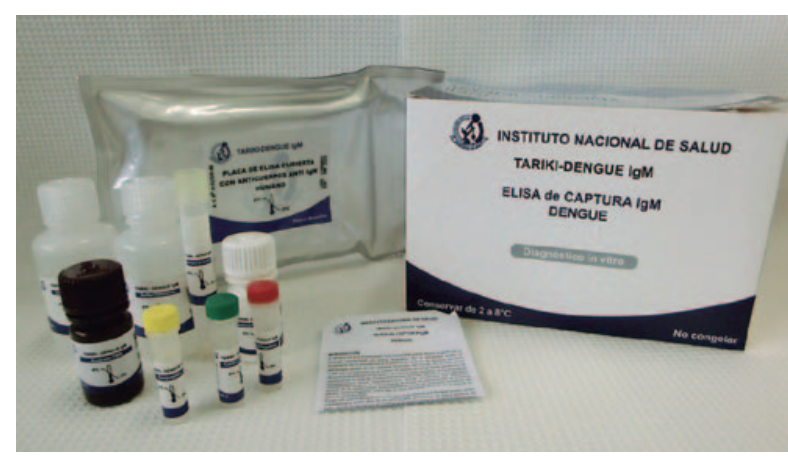

Figura 7. Componentes del Kit Tariki-Dengue para la determinación de anticuerpos IgM.

Fuente: Instituto Nacional de Salud.

indirecta demostrando la presencia de anticuerpos, a través de pruebas inmunoenzimáticas (ELISA) o Inhibición de la hemaglutinación (IHA) o neutralización en placas (PRNT) y microneutralización ${ }^{(46)}$.

Las pruebas de diagnóstico deben aplicarse según el tiempo de enfermedad, así el aislamiento viral, la detección de RNA por PCR y la detección de antígenos pueden hacerse en los primeros cinco días, y a partir del quinto día en promedio el uso de pruebas para la detección de anticuerpos IgM. En infección secundaria los anticuerpos IgG aparecen junto a los anticuerpos IgM y persisten indefinidamente.

En el Perú, se ha desarrollado una prueba ELISA de captura que detecta anticuerpos IgM (MAC ELISA) como kit de diagnóstico (TARIKI-DENGUE), que presenta una sensibilidad de $96 \%$ y una especificidad del $98 \%$, es una prueba que nos ayuda en el diagnóstico y la vigilancia de dengue y se tiene distribuida a la red de laboratorios del país ${ }^{(47)}$. La prueba fue desarrollada en el Laboratorio de Referencia Nacional de Metaxénicas Virales del Instituto Nacional de Salud (Figura 7) y es producido por el Centro de Producción de Biológicos del mismo INS.

Finalmente, se cuenta con pruebas rápidas comerciales que detectan el antígeno NS1 y anticuerpos lgM e lgG. $\mathrm{Si}$ bien en trabajos de laboratorio estas pruebas tienen una alta sensibilidad y especificidad, en condiciones de campo la sensibilidad puede no sobrepasar el $60 \%$, por lo que debemos considerar también en contexto en el que se utilizan.

\section{MANEJO DEL DENGUE}

El manejo adecuado de los pacientes depende del reconocimiento precoz de las señales de alarma, según la nueva clasificación de la OMS ${ }^{(35)}$. Los 
pacientes con señales de alarma y dengue grave requieren hospitalización; en casos de epidemias es importante la organización de los servicios en todos sus niveles, de modo que todos los casos de dengue sin señales de alarma sean vistos en el primer nivel de atención.

Si bien no hay tratamiento etiológico contra el dengue, la restauración adecuada y oportuna del volumen plasmático circulante en fases iniciales de la enfermedad es esencial para evitar la progresión a formas graves. La reposición de fluidos constituye la intervención más eficaz para la reducción de mortalidad por dengue, así tenemos que la hidratación oral disminuye el ingreso hospitalario y la severidad del cuadro clínico, y en dengue grave los cristaloides son tan efectivos como los coloides, en la reposición de fluidos ${ }^{(48)}$.

\section{PREVENCIÓN Y CONTROL VECTORIAL}

Evidentemente, el único método para controlar o prevenir la transmisión de los virus del dengue consiste en la lucha contra el Aedes aegypti. Este control de los vectores debe estar basado en la gestión del medioambiente y los métodos químicos. La eliminación adecuada de los residuos sólidos y la mejora de las prácticas de almacenamiento de agua, entre ellas la cobertura de los envases para evitar que los mosquitos hembra pongan sus huevos, son medidas que deben fomentarse en los programas comunitarios. Para ello, es imprescindible la educación, la promoción y la participación comunitaria en la lucha contra el vector, que no solo es una tarea del sector salud.

Las medidas de control vectorial dependerán del contexto en el que se desarrolla el vector, así, en las zonas como Lima donde no hay lluvias, es importante evitar la proliferación de larvas en recipientes de agua para uso en zonas periféricas, procurando que los tanques bajos y otros recipientes estén cubiertos adecuadamente para evitar que los mosquitos hembras ovipositen en ellos, este control incluye el uso de larvicidas como el temephos, debiendo contar con el convencimiento y la aceptación militante de la población.

En áreas lluviosas, como son las localidades de la Amazonía, una medida preventiva eficaz es la eliminación de inservibles que se convierten en reservorios del agua de lluvia y se comportan como criaderos, complementado también con el uso de abate en recipientes que son de uso humano, pues también tienen la necesidad de almacenar agua en zonas donde no hay opción de agua por tuberías.
El uso de insecticidas para eliminar mosquitos adultos solo está justificado cuando se está frente a epidemias, para un control inmediato de la transmisión. Es evidente que si se actúa previamente, eliminando criaderos y al vector en su estadio larvario se evitará la presencia del vector adulto.

Es importante destacar la sistematización de experiencias sobre control vectorial del dengue en la Amazonía peruana en la que participaron las direcciones regionales de salud (DIRESA), el Ministerio de Salud (MINSA) y la Organización Panamericana de la Salud (OPS), siendo relevante la reflexión sobre dicho trabajo orientada a la acción que articule una mejor comprensión de las determinantes sociales y ambientales desde una perspectiva ecosistémica que promueva espacios permanentes y colaborativos de planificación estratégica y toma de decisiones oportunas, tomando en cuenta: el mejorar la comprensión de las determinantes sociales y ambientales desde un enfoque ecosistémico; la promoción de la sensibilización estratégica de los tomadores de decisión y de la población para mejorar su participación; la construcción de información y conocimiento de calidad para la planificación estratégica y la toma de decisiones; la sistematización y divulgación de las iniciativas de innovaciones regionales de los procesos de vigilancia y control vectorial; la promoción de espacios permanentes y colaborativos de planificación estratégica y toma de decisiones; e impulsar la investigación orientadas a la acción.

\section{VACUNAS Y ANTIVIRALES CONTRA EL DENGUE}

Aún no hay ninguna vacuna con licencia disponible contra el dengue; sin embargo, hay varias vacunas que están en desarrollo, estas incluyen vacunas vivas atenuadas del virus, vacunas virales quiméricas en vivo, las vacunas de virus inactivadas, $y$ vivas recombinantes, de ADN y vacunas de subunidades ${ }^{(49,50)}$ de los cuatro serotipos y la interferencia viral entre los cuatro serotipos en formulaciones tetravalentes. Últimos reportes de ensayos clínicos de fase 3 han mostrado una eficacia de alrededor $60 \%$ de una vacuna tetravalente viva atenuada en países del Asia y América ${ }^{(51,52)}$.

También se han propuesto y desarrollado por razones de seguridad vacunas no virales, que incluye vacunas de subunidades que, en su mayoría, se centraron en la proteína $\mathrm{E}$ o sus derivados. Sin embargo, la dificultad de producir niveles equilibrados de neutralizar anticuerpos a cada uno de los cuatro serotipos sigue siendo una preocupación importante. El AgNS1 es otro candidato para vacuna segura, pues al no ser una proteína asociada con el virión no desencadenaría efectos de inmunoamplificación (ADE) ${ }^{(53)}$. 
Por otro lado, el análisis del ciclo de vida del virus dengue evidencia niveles importantes que pueden ser blancos de antivirales, como: entrada del virus, fusión de membranas, replicación del genoma ARN, ensamblaje y liberación final por la célula infectada. Estudios recientes han mostrado resultados alentadores utilizando un análogo de nucleósido, la 2'-C-metilcitidina en estudios en monos ha mostrado la replicación viral ${ }^{(54)}$, o una combinación de análogos de nucleósido con inhibidores de la síntesis de nucleósido ${ }^{(55)}$. En general, un mejor entendimiento de los mecanismos patogénicos en dengue proveerá herramientas valiosas para el desarrollo de antivirales y vacunas.
Contribuciones de autoría: CCS y VFS han participado en la concepción y diseño del artículo, obtención de resultados, redacción del artículo, revisión crítica del artículo y la aprobación de su versión final. MG-M, MPS, EMZ y FDT han participado en la obtención de resultados, análisis e interpretación de datos, redacción del artículo y aprobación de su versión final.

Fuentes de financiamiento: autofinanciamiento.

Conflictos de interés: los autores declaran no tener conflictos de interés.

\section{REFERENCIAS BIBLIOGRÁFICAS}

1. World Health Organization. Dengue, countries or areas at risk, 2013 [Internet]. Geneva: WHO; 2014 [citado el 15 de enero de 2015]. Disponible en: http://www.who.int/ ith/en/

2. World Health Organization. Global strategy for dengue prevention and control 2012-2020. Geneva: WHO; 2012.

3. Shepard DS, Coudeville L, Halasa YA, Zambrano B, Dayan GH. Economic impact of dengue illness in the Americas. Am J Trop Med Hyg. 2011 Feb;84(2):200-7. doi: 10.4269/ ajtmh.2011.10-0503.

4. PAHO/WHO. Los casos de dengue en las Américas se quintuplicaron en diez años, según nuevos datos de la OPS/ OMS. Washington, D.C: PAHO; 2014.

5. PAHO/WHO. Number of Reported Cases of Dengue and Severe Dengue (SD) in the Americas, by Country: Epidemiological Week / EW 53 (Updated Jan 19, 2015). Washington, D.C.: PAHO; 2015. Disponible en: http://www.paho.org

6. PAHO/WHO. Descripción de la situación epidemiológica actual del dengue en las Américas. Washington, DC: PAHO; 2014.

7. Schneider J, Droll D. A timeline for dengue in the Americas to december 31, 2000 and noted first occurences. Washington, DC: PAHO; 2001.

8. Durand-Velazco S, Fiestas-Solorzano V, Sihuincha-Maldonado M, Chavez-
Lencinas C, Vasquez-Vela V, TorrejonFlores $\mathrm{C}$, et al. Impacto de la epidemia de dengue con un nuevo linaje del DENV-2 Genotipo Americano / Asiático en la demanda de servicios del hospital de Apoyo de Iquitos "Cesar Garayar García”. Rev Peru Med Exp Salud Publica. 2011;28(1):157-9.

9. Mamani E, Álvarez C, García MM, Figueroa D, Gatti M, Guio H, et al. Circulación de un linaje diferente del virus dengue 2 genotipo América / Asia en la region amazónica del Perú, 2010. Rev Peru Med Exp Salud Publica. 2011;28(1):72-7.

10. Perú, Ministerio de Salud. Incidencia acumulada de dengue sin señales de alarma, con señales de alarma y dengue grave por regiones en el Perú 2011. Bol Epidemiol (Lima). 2011;20(52).

11. Perú, Ministerio de Salud. Resumen de las enfermedades o eventos bajo vigilancia epidemiológica en el Perú. Bol Epidemiol (Lima). 2014;23(22):442-6.

12. Brathwaite Dick O, San Martin JL, Montoya RH, del Diego J, Zambrano B, Dayan GH. The history of dengue outbreaks in the Americas. Am J Trop Med Hyg. 2012 Oct;87(4):584-93. doi: 10.4269/ajtmh.2012.11-0770.

13. Perú, Ministerio de Salud. Aprendiendo de la experiencia: lecciones aprendidas para la preparación y respuesta en el control vectorial ante brotes de dengue en el Perú. Lima: MINSA; 2011.

14. Yáñez P, Mamani E, Valle J, García MP, León W, Villaseca $\mathrm{P}$, et al. Variabilidad genetica del Aedes aegypti determinada mediante el analisis del gen mitocondrial ND4 en once areas endemicas para dengue en el Perú. Rev Peru Med Exp Salud Publica. 2013;30(2):246-50.

15. Leiva N, Cáceres O. Variabilidad genética de Aedes aegypti en algunas áreas del Perú usando Single Stranded Conformational Polymorphism (SSCP). Rev Peru Med Exp Salud Publica. 2004;21(3).157-66.

16. Braga IA, Valle D. Aedes aegypti: inseticidas, mecanismos de ação e resistência. Epidemiol Serv Saúde. 2007;16(4):279-93.

17. Lima EP, Paiva MH, de Araujo AP, da Silva EV, da Silva UM, de Oliveira LN, et al. Insecticide resistance in Aedes aegypti populations from Ceara, Brazil. Parasit Vectors. 2011 Jan 12;4:5. doi: 10.1186/1756-3305-4-5.

18. Santacoloma Varon L, Chaves Cordoba B, Brochero HL. Susceptibilidad de Aedes aegypti a DDT, deltametrina y lambdacialotrina en Colombia. Rev Panam Salud Publica. 2010;27(1):66-73.

19. Bisset JA, Rodríguez MM, Fernández D, Palomino M. Resistencia a insecticidas y mecanismos de resistencia en Aedes aegypti (Diptera: Culicidae) de 2 provincias del Perú. Rev Cubana Med Trop. 2007;59(3):202-8.

20. Normile D. Tropical medicine. Surprising new dengue virus throws a spanner in disease control efforts. Science. 2013 Oct 25;342(6157):415. doi: 10.1126/science.342.6157.415.

21. Mustafa MS, Rasotgi V, Jain S, 
Gupta V. Discovery of fifth serotype of dengue virus (DENV-5): A new public health dilemma in dengue control. Med J Armed Forces India. 2015 Jan;71(1):67-70. doi: 10.1016/j. mjafi.2014.09.011.

22. Lindenbach BD, Murray C, Thiel HJ, Rice C. Flaviviridae. Fields Virology. Philadelphia: Lippincott William \& Wilkins, Wolters Kluwer; 2013.

23. Wu SJ, Grouard-Vogel G, Sun W, Mascola JR, Brachtel E, Putvatana R, et al. Human skin Langerhans cells are targets of dengue virus infection. Nat Med. 2000 Jul;6(7):816-20.

24. Carrington LB, Simmons CP. Human to mosquito transmission of dengue viruses. Front Immunol. 2014 Jun 17;5:290. doi: 10.3389/ fimmu.2014.00290.

25. Phillips I, Need J, Escamilla J, Colan E, Sanchez S, Rodriguez M, et al. First documented outbreak of dengue in the Peruvian Amazon region. Bull Pan Am Health Organ. 1992;26(3):201-7.

26. Watts D, Ramírez G, Cabezas C, Wooster M. Arthropod-borne diseases in Peru. En: Travassos da Rosa A, Vasconcelos P, Travassos da Rosa J. An overview of arbovirology in Brazil and neighboring countries. Belém: Instituto Evandro Chagas; 1998. p. 193-218.

27. Hayes CG, Phillips IA, Callahan JD, Griebenow WF, Hyams KC, Wu SJ, et al. The epidemiology of dengue virus infection among urban, jungle, and rural populations in the Amazon region of Peru. Am J Trop Med Hyg. 1996 Oct;55(4):459-63.

28. Kochel TJ, Watts DM, Halstead SB, Hayes CG, Espinoza A, Felices V, et al. Effect of dengue-1 antibodies on American dengue-2 viral infection and dengue haemorrhagic fever. Lancet. 2002 Jul 27;360(9329):310-2

29. Watts DM, Porter KR, Putvatana P, Vasquez B, Calampa C, Hayes CG, et al. Failure of secondary infection with American genotype dengue 2 to cause dengue haemorrhagic fever. Lancet. 1999 Oct;354(9188):1431-4.

30. Montoya Y, Holechek S, Caceres O, Palacios A, Burans J, Guevara C, et al. Circulation of Dengue Viruses in North-Western Peru, 2000-2001. Dengue Bulletin. 2003;27:52-62.

31. Cruz CD, Forshey BM, Juarez DS,
Guevara C, Leguia M, Kochel TJ, et al. Molecular epidemiology of American/Asian genotype DENV2 in Peru. Infect Genet Evol. 2013 Aug;18:220-8. doi: 10.1016/j. meegid.2013.04.029.

32. Kochel T, Aguilar P, Felices V, Comach G, Cruz C, Alava A, et al. Molecular epidemiology of dengue virus type 3 in Northern South America: 2000--2005. Infect Genet Evol. 2008 Sep;8(5):6828. doi: 10.1016/j.meegid.2008.06.008.

33. Forshey BM, Morrison AC, Cruz C, Rocha C, Vilcarromero S, Guevara $\mathrm{C}$, et al. Dengue virus serotype 4, northeastern Peru, 2008. Emerg Infect Dis. 2009 Nov;15(11):1815-8. doi: 10.3201/eid1511.090663.

34. Mamani E. Identificación de genotipos y linajes de los cuatro serotipos del virus dengue en el Perú durante los años 1998-2012. Tesis para obtener el grado de Doctor. Facultad de Medicina, Universidad Nacional Mayor de San Marcos. Lima, Perú. 2013.

35. World Health Organization. Dengue: guidelines for diagnosis, treatment, prevention and control. Geneva: WHO; 2009.

36. Fiestas Solorzano V, Sihuincha Maldonado M, Donaires Toscano F, Durand Velazco S, Garcia MM, Mamani E, et al. Características clínicas de pacientes internados en el Hospital de Apoyo de Iquitos "Cesar Garayar Garcia” durante la epidemia de dengue, enero-febrero de 2011. Rev Peru Med Exp Salud Publica. 2011;28(1):78-82.

37. Gandini M, Gras C, Azeredo EL, Pinto LM, Smith N, Despres P, et al. Dengue virus activates membrane TRAIL relocalization and IFN- $\alpha$ production by human plasmacytoid dendritic cells in vitro and in vivo. PLoS Negl Trop Dis. 2013 Jun 6;7(6):e2257. doi: 10.1371/ journal.pntd.0002257.

38. Srikiatkhachorn A, Green S. Markers of dengue disease severity. Curr Top Microbiol Immunol. 2010;338:67-82. doi: 10.1007/978-3-642-02215-9 6 .

39. Yauch LE, Prestwood TR, May MM, Morar MM, Zellweger RM, Peters B, et al. CD4+ $\mathrm{T}$ cells are not required for the induction of dengue virusspecific CD8+ $T$ cell or antibody responses but contribute to protection after vaccination. J Immunol. 2010 Nov 1;185(9):5405-16. doi: 10.4049/ jimmunol.1001709.

40. Sihuincha Maldonado M, Fiestas Solórzano V, Durand Velazco S, Garcia MM, Gatti M. Niveles de células CD4 en pacientes hospitalizados con diagnóstico de dengue en el Hospital de Apoyo de Iquitos César Garayar García. Rev Peru Med Exp Salud Publica. 2011;28(1):156-7.

41. Torrentes-Carvalho A, Azeredo EL, Reis SR, Miranda AS, Gandini M, Barbosa LS, et al. Dengue-2 infection and the induction of apoptosis in human primary monocytes. Mem Inst Oswaldo Cruz. 2009 Dec;104(8):1091-9.

42. Basu A, Jain P, Gangodkar SV, Shetty S, Ghosh K. Dengue 2 virus inhibits in vitro megakaryocytic colony formation and induces apoptosis in thrombopoietin-inducible megakaryocytic differentiation from cord blood CD34+ cells. FEMS Immunol Med Microbiol. 2008 Jun;53(1):46-51. doi: 10.1111/j.1574695X.2008.00399.x.

43. Tsai JJ, Liu LT, Chang K, Wang SH, Hsiao HM, Clark KB, et al. The importance of hematopoietic progenitor cells in dengue. Ther Adv Hematol. 2012 Feb;3(1):59-71. doi: 10.1177/2040620711417660.

44. Hottz E, Tolley ND, Zimmerman GA, Weyrich AS, Bozza FA. Platelets in dengue infection. Drug Discovery Today: Disease Mechanisms. 2011;8(1-2):e33-e8.

45. Srichaikul T, Nimmannitya $S$ Haematology in dengue and dengue haemorrhagic fever. Baillieres Best Pract Res Clin Haematol. 2000 Jun;13(2):261-76.

46. Organización Panamericana de la Salud. Dengue Guías de atención para enfermos de dengue en la región de las Américas. Bolivia: Washington, DC; 2010.

47. Cabezas-Sánchez C. Enfermedades infecciosas desatendidas: un permanente reto para la salud pública y la equidad en el Perú. Rev Peru Med Exp Salud Publica. 2014;31(2):326-35.

48. Donaires F, Fiestas V, Pachas P, Zavala R, López J, Suárez V; Perú, Ministerio de Salud. Revisión sistemática sobre la terapia de reposición de fluidos en los pacientes con dengue según gravedad: Notas técnicas [Internet]. 
Lima: MINSA; 2012 [citado el 24 de febrero del 2015]. Disponible en: http://www.ins.gob.pe/ repositorioaps/0/4/jer/evidencias/ NOTA $\% 20$ T\% $3 \% 89$ CNICA\%20 N\%C2\%B0\%2001\%20-2012.pdf

49. Murrell S, Wu SC, Butler M. Review of dengue virus and the development of a vaccine. Biotechnol Adv. 2011 MarApr;29(2):239-47. doi: 10.1016/j. biotechadv.2010.11.008.

50. Yauch LE, Shresta S. Dengue virus vaccine development. Adv Virus Res. 2014;88:315-72. doi: 10.1016/B9780-12-800098-4.00007-6.

51. Villar L, Dayan GH, Arredondo-Garcia JL, Rivera DM, Cunha R, Deseda C, et al. Efficacy of a tetravalent dengue vaccine in children in Latin America. $\mathrm{N}$
Engl J Med. 2015 Jan 8;372(2):113-23. doi: 10.1056/NEJMoa1411037.

52. Capeding MR, Tran NH, Hadinegoro SR, Ismail HI, Chotpitayasunondh T, Chua MN, et al. Clinical efficacy and safety of a novel tetravalent dengue vaccine in healthy children in Asia: a phase 3, randomised, observer-masked, placebo-controlled trial. Lancet. 2014 Oct 11;384(9951):1358-65. doi: 10.1016/S0140-6736(14)61060-6.

53. Murphy BR, Whitehead SS. Immune response to dengue virus and prospects for a vaccine. Annu Rev Immunol. 2011;29:587-619. doi: 10.1146/ annurev-immunol-031210-101315.

54. Lee JC, Tseng CK, Wu YH, KaushikBasu N, Lin CK, Chen WC, et al. Characterization of the activity of
2'-C-methylcytidine against dengue virus replication. Antiviral Res. 2015 Apr;116:1-9. doi: 10.1016/j. antiviral.2015.01.002.

55. Yeo KL, Chen YL, Xu HY, Dong H, Wang QY, Yokokawa F, et al. Synergistic suppression of dengue virus replication using a combination of nucleoside analogs and nucleoside synthesis inhibitors. Antimicrob Agents Chemother. 2015 Apr;59(4):2086-93. doi: 10.1128/AAC.04779-14.

Correspondencia: César Cabezas Sánchez

Dirección: Av. Cápac Yupanqui 1400, Lima 11, Perú.

Teléfono: 998880403

Correoelectrónico:ccabezas@ins.gob.pe

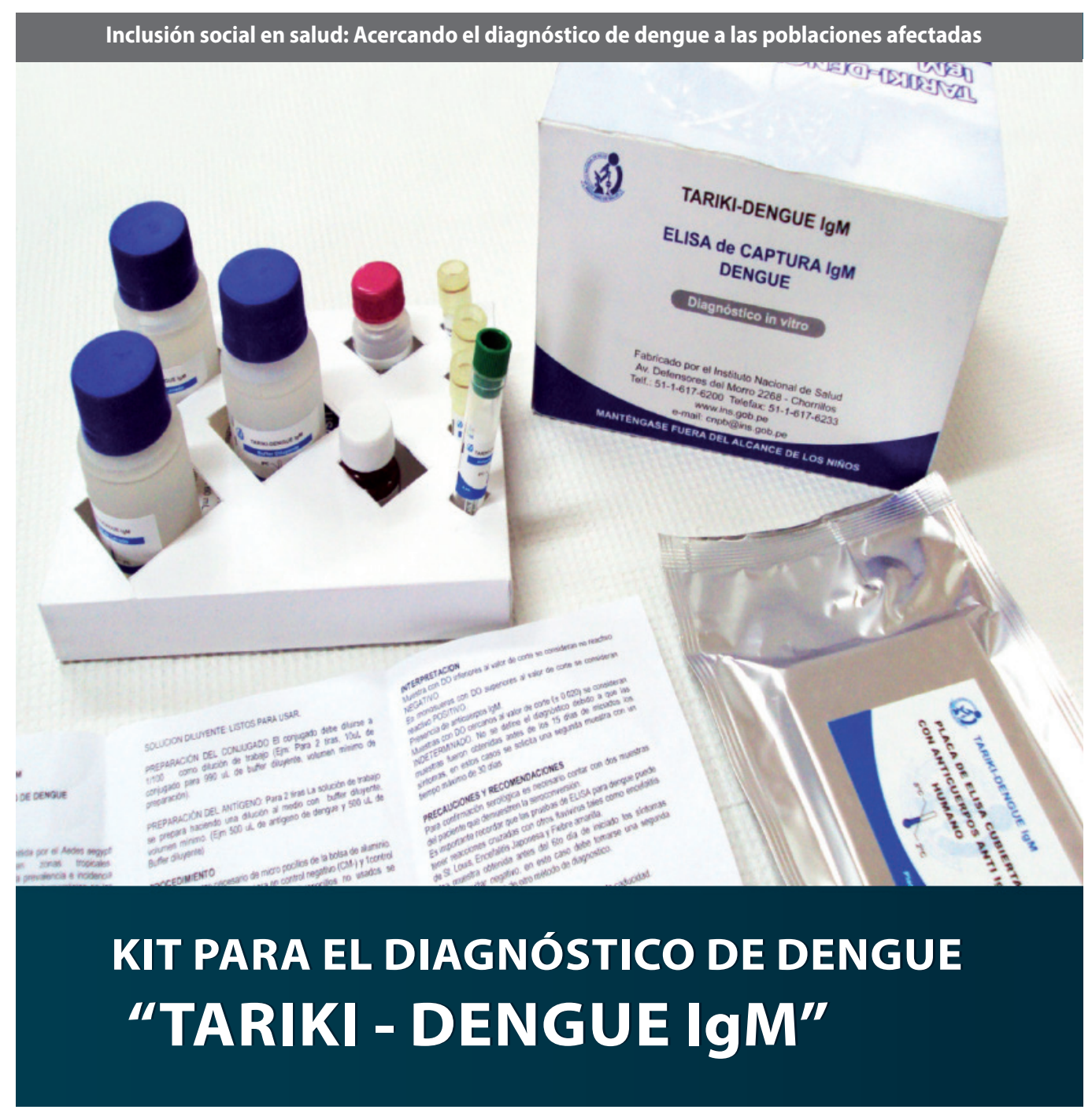

